\title{
REVIEW
}

\section{Incretin-Based Therapies: Focus on Effects Beyond Glycemic Control Alone}

\author{
Jaime A. Davidson
}

To view enhanced content go to www.diabetestherapy-open.com

Received: June 26, 2013 / Published online: September 21, 2013

(C) The Author(s) 2013. This article is published with open access at Springerlink.com

\section{ABSTRACT}

Type 2 diabetes is associated with a high prevalence of comorbidities resulting from hypertension, dyslipidemia, and hyperglycemia. Inadequate management of these risk factors will eventually result in detrimental health consequences. Thus, the effect of a drug on factors such as weight, cardiovascular $(\mathrm{CV})$ risk factors, and adherence is important to consider. A review was undertaken of the recent medical literature describing the extraglycemic characteristics of the two classes of incretin-based therapiesglucagon-like peptide-1 receptor agonists (GLP1RA) and dipeptidyl peptidase-4 (DPP-4) inhibitors. PubMed searches were performed to identify published data on incretin therapies

J. A. Davidson ( $\square)$

Division of Endocrinology, University of Texas Southwestern Medical Center, 5323 Harry Hines Blvd. K5.246, Dallas, TX 75235-8857, USA

e-mail: Jaime.Davidson@UTSouthwestern.edu that describe their effects on $\mathrm{CV}$ risk factors, $\mathrm{CV}$ events, and factors related to medication adherence. The maintenance or loss of weight associated with the use of GLP-1RAs and DPP-4 inhibitors is well described in the medical literature. These agents also appear to be associated with a modest decrease in blood pressure and a reduced risk of $\mathrm{CV}$ events. In addition, several characteristics of incretin therapies may improve rates of medication adherence, such as generally favorable tolerability profiles (particularly with DPP-4 inhibitors), the availability of formulations that simplify treatment regimens, and a low risk for hypoglycemia. The literature on incretin therapies describes a number of clinical characteristics that are relevant to the management of extraglycemic risk factors. As part of a holistic treatment strategy, these properties constitute important considerations for tailoring therapy to individual patients with type 2 diabetes.

Keywords: Dipeptidyl peptidase-4; Glucagonlike peptide-1; Incretin therapies; Type 2 diabetes 


\section{INTRODUCTION}

The high prevalence of comorbidities associated with type 2 diabetes exerts a significant socioeconomic burden on the US healthcare system. For example, diabetes is the leading cause of end-stage renal disease [1]. One retrospective study of $>91,000$ patient records reported an incidence of chronic kidney disease of $\sim 15 \%$ in individuals with both type 2 diabetes and hypertension, compared with only $1.1 \%$ and $1.5 \%$ in patients with diabetes or hypertension alone, respectively [2]. Diabetes is also a leading cause of blindness in US adults. A recent pooled analysis of data from more than 23,000 patients reported that the prevalence of diabetic retinopathy may be as high as 35\% [3]. Approximately 7 million patients with diabetes had retinal disease in 2005, and it has been predicted that this number will increase to 19 million by the year 2050 [4].

Against this background, physicians must take into consideration a complex set of variables when discussing treatment options with patients who have type 2 diabetes. In the current era of medical research, the clinical and pharmacologic characteristics of antidiabetic agents are being evaluated in greater depth than just a few decades ago and, as a result, our understanding of these medicines now extends far beyond their role in glycemic control.

While the effects of a drug on factors such as weight, cardiovascular (CV) risk, and medication adherence were once considered secondary to the efficacy of the drug for reducing blood glucose, now many patients and physicians consider such factors when choosing medications to meet agreed upon therapy goals. In this regard, incretin-based therapies have demonstrated a favorable set of clinical characteristics that are well suited to this type of holistic approach to the management of type 2 diabetes. The aim of this article is to review the recent medical literature describing such characteristics for the two classes of incretin-based therapiesglucagon-like peptide-1 receptor agonists (GLP1RA) and dipeptidyl peptidase-4 (DPP-4) inhibitors.

\section{MATERIALS AND METHODS}

PubMed searches were conducted for literature describing the extraglycemic effects of incretinbased therapies. The following terms were used to search among English language publication titles in the PubMed database: (incretin[ti] OR glp-1[ti] OR exenatide[ti] OR liraglutide[ti] OR (glucagon[ti] AND peptide[ti])); (dipeptidyl[ti] OR dpp-4[ti] OR sitagliptin[ti] OR saxagliptin[ti] OR vildagliptin[ti] OR linagliptin[ti]); (tolerab* OR [effect* AND side OR adverse]) AND (discontin* [ti] OR adher* [ti] OR non-adher* [ti] OR nonadher* [ti] OR complian* [ti]); (weight [ti] OR bmi [ti] OR body mass [ti]); (cardiovasc*[ti] OR lipid*[ti] OR pressure[ti] OR cholesterol[ti]). When needed for more targeted searches, results were restricted to clinical trials or were expanded to title/abstract using the appropriate PubMed limiters. Initial literature searches were conducted from 30 August to 18 December 2012, with additional searches on specific topics as required to update the review. No date restrictions were specified. PubMed abstracts were qualitatively reviewed and individually selected based on their relevance to the review topic. Articles that were considered relevant based on an assessment of an abstract were obtained and further evaluated, with attention to references cited for further resources. 


\section{CARDIOVASCULAR RISK}

\section{Weight}

In obese individuals, the risk of developing type 2 diabetes is elevated $\sim$ sevenfold relative to those with normal body weight [5]. The presence of diabetes and obesity elevates the risk (individually and in combination) of numerous complications and comorbidities, including CV disease, hypertension, and stroke. Cardiovascular disease alone is responsible for $\sim 65 \%$ of deaths in patients with type 2 diabetes [6]. Therefore, given that most individuals with type 2 diabetes are obese, weight reduction is a key strategy to reduce morbidity and mortality.

The Action for Health in Diabetes (Look AHEAD) study was designed to provide a quantitative assessment of the association between modest weight reduction in overweight/obese patients with type 2 diabetes and the incidence of severe $\mathrm{CV}$ events (heart disease, stroke, and CV-related deaths). The study began in 2001 and was scheduled to complete in 2014. In the first year of Look AHEAD, patients participating in intensive lifestyle intervention $(N=2,503)$ lost $\sim 7-9 \%$ of body weight [7]. This was associated with a $25-33 \mathrm{mg} / \mathrm{dL}$ decrease in serum triglycerides (TG) and a 5-8 $\mathrm{mmHg}$ reduction in systolic blood pressure (SBP). As a reference for the clinical relevance of this magnitude of blood pressure (BP) reduction, in the United Kingdom Prospective Diabetes Study (UKPDS), each $10 \mathrm{mmHg}$ reduction in SBP was associated with an $11 \%$ reduced risk of myocardial infarction, a $12 \%$ reduction in the risk of any diabetes complications, and a $13 \%$ reduction in the risk for microvascular disease [8]. In addition, the $7-9 \%$ reduction in body weight in Look AHEAD was also associated with a
2-5 mg/dL increase in high-density lipoprotein cholesterol (HDL-C), and a 4-7 mg/dL decrease in low-density lipoprotein cholesterol (LDL-C) [7]. For reference, note that a $23-\mathrm{mg} / \mathrm{dL}$ decrease in total cholesterol (TC) can reduce the risk of coronary heart disease by up to $30 \%$ [9-12]. Thus, significant improvements in $\mathrm{CV}$ risk factors may be achieved through modest reductions in body weight.

The Look AHEAD study was terminated early based on the results of an interim analysis [13]. It was determined that the rate of severe $\mathrm{CV}$ events in the treatment group (intensive lifestyle intervention) was not significantly different from that in the control group (diabetes support and education) and that given the 11-year study duration, this was not likely to change. Although the intensive lifestyle intervention has been discontinued, patients will continue with follow-up as a means of assessing any potential long-term effects of the intervention, for example, through metabolic memory (the 'legacy effect'). The results of the long-term follow-up of patients participating in Look AHEAD will help to more specifically inform treatment decisions related to lifestyle intervention.

Clinically significant weight loss is potentially within the pharmacologic effect of GLP-1RAs (Fig. 1). In clinical trials, weight loss with exenatide [14-17] and liraglutide have generally ranged from $2 \%$ to $4 \%$ of initial body mass (Table 1) [14-54]. The Liraglutide Effect and Action in Diabetes (LEAD) trials showed that up to one-quarter of patients lost $>5 \%$ of body weight over 26 weeks [55]. Patients participating in clinical trials of linagliptin, saxagliptin, and sitagliptin have typically shown a $-1 \%$ to $+1 \%$ change in body weight (Table 1; Fig. 1), and thus these agents are considered weight-neutral. Considering the important benefits of weight 
loss, and conversely the increased health risks associated with further weight gain, these features of incretin therapies represent an important consideration for patients with (or at risk for developing) CV disease. This is in contrast to several other classes of therapy; for example, the use of insulin, sulfonylureas (SUs), and thiazolidinediones is associated with weight gain. Although it has not been demonstrated that the magnitude of weight gain associated with any antihyperglycemic therapy leads to a significant increase in the risk of $\mathrm{CV}$ disease/events, it nevertheless remains an essential goal of therapy for patients with type 2 diabetes to achieve some degree of weight loss-or at the very least to prevent further weight gain [56]. In settings in which agents that induce weight gain must be used (for example, as the result of driving factors such as tolerance or medication history), the concomitant use of incretin-based therapies should be considered as a means to minimize additional weight gain.

In this regard, several studies have demonstrated the weight-mitigating effects of incretin therapies when used in conjunction with insulin. As a recent example, Lind et al. [57] examined the effects of adding exenatide $(n=21) \quad$ or liraglutide $(n=40)$ to the antihyperglycemic regimen of patients taking insulin and permissibly other oral antidiabetic drugs (OADs). Most patients (69\%) were taking metformin and multiple daily insulin injections (53\%); fewer were taking a basal insulin only (34\%) or an SU (2\%). After a mean of 7 months, weight decreased by $7 \mathrm{~kg}$ (15 lbs; 6\% of initial

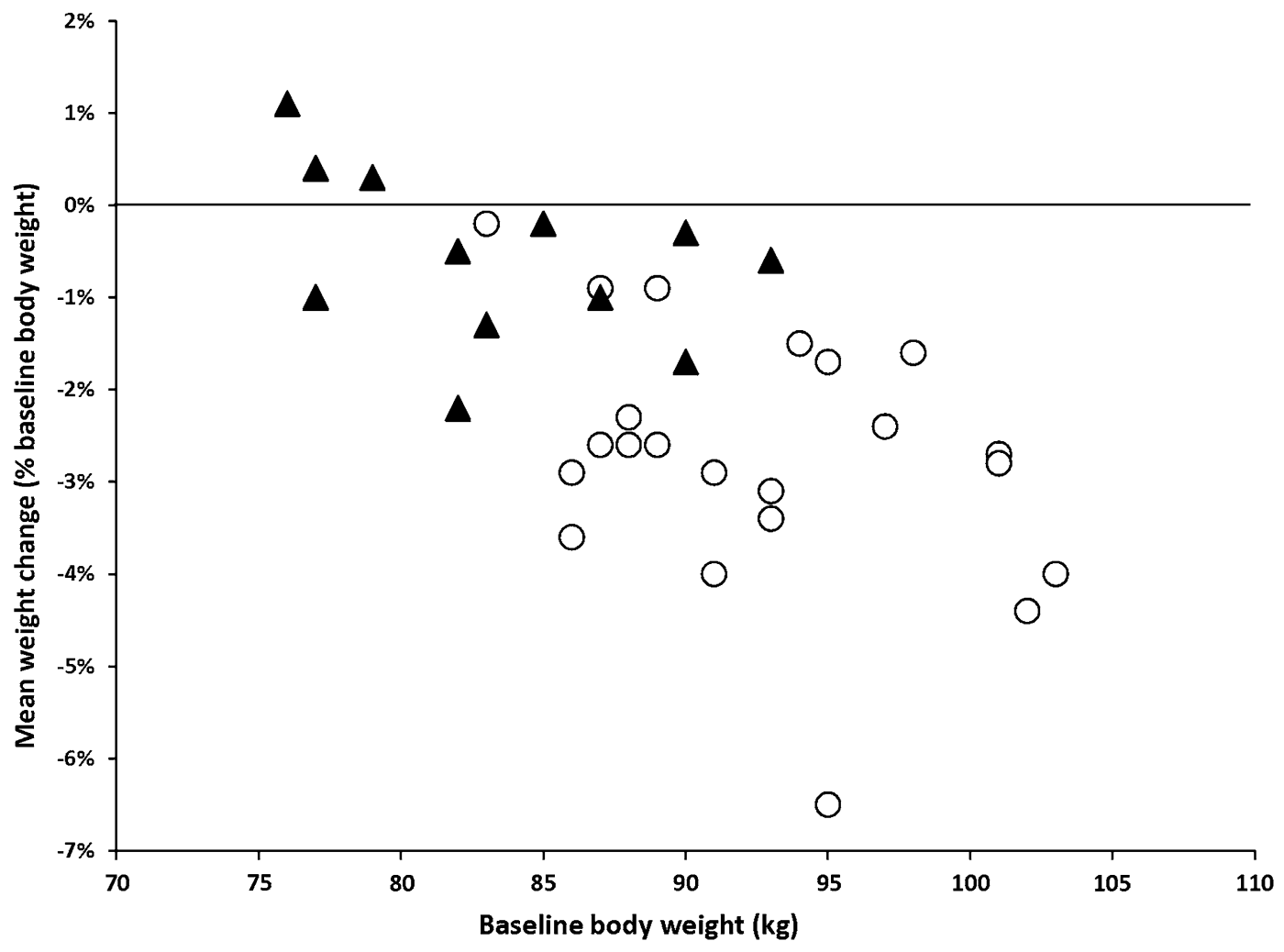

Fig. 1 Weight change with incretin therapies as a function of baseline body weight. Data correspond to the studies described in Table 1. Data shown for DPP-4 inhibitors (solid triangles) and GLP-1RAs (open circles). GLP-1RA glucagon-like peptide-1 receptor agonists, DPP-4 dipeptidyl peptidase-4 
Table 1 Weight changes with incretin therapies

\begin{tabular}{|c|c|c|c|c|}
\hline & Study & Treatment & $\begin{array}{l}\text { Baseline } \\
\text { weight (kg) }\end{array}$ & $\begin{array}{l}\text { Mean weight change } \\
\text { in } \mathrm{kg} \text { (\% body weight) }\end{array}$ \\
\hline \multicolumn{5}{|l|}{ GLP-1RA } \\
\hline \multirow[t]{16}{*}{ Liraglutide } & LEAD-1: & Lira $1.8 \mathrm{mg}+\mathrm{SU}$ & 83 & $-0.2(-0.2)$ \\
\hline & Marre et al. [18] & Rosi $+\mathrm{SU}$ & 81 & $+2.1(+2.6)$ \\
\hline & LEAD-2: & Lira $1.8 \mathrm{mg}+$ Met & NR & -2.8 \\
\hline & Nauck et al. [19] & Placebo comparator & & -1.5 \\
\hline & & SU comparator & & +1.0 \\
\hline & LEAD-3: & 1.8-mg Lira monotherapy & 93 & With nausea $>7$ days: $-3.4(-3.6)$ \\
\hline & Garber et al. [20] & & & With nausea $\leq 7$ day: $-2.3(-2.4)$ \\
\hline & & SU comparator & 93 & With nausea $>7$ days: $-1.4(-1.5)$ \\
\hline & & & & With nausea $\leq 7$ days: $+1.2(+1.3)$ \\
\hline & LEAD-4: & Lira $1.8 \mathrm{mg}+$ Met + TZD & NR & -2.0 \\
\hline & Zinman et al. [21] & Placebo comparator & & +0.6 \\
\hline & LEAD-5: & Lira $1.8 \mathrm{mg}+\mathrm{Met}+\mathrm{SU}$ & 86 & $-1.8(-2.1)$ \\
\hline & Russell-Jones et al. [22] & Placebo comparator & 86 & $-0.42(-0.49)$ \\
\hline & & Insulin glargine comparator & 85 & $+1.6(+1.9)$ \\
\hline & LEAD-6: & Lira $1.8 \mathrm{mg}$ & 93 & $-3.2(-3.4)$ \\
\hline & Buse et al. [23] & Exe comparator & 93 & $-2.9(-3.1)$ \\
\hline \multirow[t]{31}{*}{ Exenatide } & DURATION-1: & Exe once weekly & 103 & $-4.1(-4.0)$ \\
\hline & Buse et al. [24] & Exe twice daily switch to once weekly & 102 & $-4.5(-4.4)$ \\
\hline & DURATION-2: & Exe once weekly & 89 & $-2.3(-2.6)$ \\
\hline & Bergenstal et al. [25] & Sita $100 \mathrm{mg}$ & 87 & $-0.8(-0.9)$ \\
\hline & & Pio & 88 & $+2.8(+3.0)$ \\
\hline & DURATION-3: & Exe once weekly & 91 & $-2.6(-2.9)$ \\
\hline & Diamant et al. [26] & Insulin glargine & 91 & $+1.4(+1.5)$ \\
\hline & DURATION-4: & Exe once weekly & 88 & $-2.0(-2.3)$ \\
\hline & Russell-Jones et al. [27] & Met & 86 & $-2.0(-2.3)$ \\
\hline & & Pio & 86 & $+1.5(+1.7)$ \\
\hline & & Sita & 89 & $-0.8(-0.9)$ \\
\hline & DURATION-5: & Exe once weekly & 97 & $-2.3(-2.4)$ \\
\hline & Blevins et al. [28] & Exe twice daily & 94 & $-1.4(-0.5)$ \\
\hline & Apovian et al. [29] & Exe $10 \mu \mathrm{g}+$ Met + SU + LM & 95 & $-6.2(-6.5)$ \\
\hline & & Placebo + Met + SU + LM & 95 & $-4.0(-4.2)$ \\
\hline & Bunck et al. [30] & Exe $10-20 \mu \mathrm{g}$ & 91 & $-3.6(-4.0)$ \\
\hline & & Insulin glargine comparator & 92 & $+1.0(+1.1)$ \\
\hline & Buse et al. [15] & Exe $10 \mu \mathrm{g}+\mathrm{SU}$ & 95 & $-1.6(-1.7)$ \\
\hline & & Placebo comparator & & \\
\hline & Davies et al. [31] & Exe $10 \mu \mathrm{g}$ & 101 & $-2.7(-2.7)$ \\
\hline & & Insulin glargine & 98 & $+3.0(+3.1)$ \\
\hline & DeFronzo et al. [16] & Exe $10 \mu \mathrm{g}+$ Met & 101 & $-2.8(-2.8)$ \\
\hline & & Placebo comparator & & \\
\hline & Gallwitz et al. [32] & Exe $10 \mu \mathrm{g}+$ Met & NR & -4.1 \\
\hline & & Insulin aspart $70 / 30+$ Met & & +1.0 \\
\hline & Glass et al. ${ }^{\mathrm{a}}[33]$ & Exe twice daily + Met $+S U$ & 87 & $-2.3(-2.6)$ \\
\hline & & $\begin{array}{l}\text { Insulin (glargine or aspart) }+ \\
\text { Met }+ \text { SU }\end{array}$ & 86 & $+1.8(2.1)$ \\
\hline & Heine et al. [14] & Exe $10 \mu \mathrm{g}$ & 88 & $-2.3(-2.6)$ \\
\hline & & Insulin glargine comparator & 88 & $+1.8(+2.0)$ \\
\hline & Kendall et al. [17] & Exe $10 \mu \mathrm{g}+\mathrm{Met}+\mathrm{SU}$ & 98 & $-1.6(-1.6)$ \\
\hline & & Placebo comparator & & \\
\hline
\end{tabular}


Table 1 continued

\begin{tabular}{|c|c|c|c|c|}
\hline & Study & Treatment & $\begin{array}{l}\text { Baseline } \\
\text { weight }(\mathbf{k g})\end{array}$ & $\begin{array}{l}\text { Mean weight change } \\
\text { in } \mathrm{kg} \text { (\% body weight) }\end{array}$ \\
\hline & Klonoff et al. [34] & Exe + multiple $^{\mathrm{b}}: 3$ years & NR & BMI <30: -3.9 \\
\hline & & & & $\mathrm{BMI} \geq 30:-5.8$ \\
\hline & Moretto et al. [35] & Exe $10 \mu \mathrm{g}$ & 86 & $-3.1(-3.6)$ \\
\hline & & Placebo comparator & 86 & $-1.4(-1.6)$ \\
\hline & Nauck et al. [36] & Exe $10 \mu \mathrm{g}+\mathrm{Met}+\mathrm{SU}$ & 86 & $-2.5(-2.9)$ \\
\hline & & $\begin{array}{l}\text { Insulin aspart }+ \text { Met }+S U \\
\text { as comparator }\end{array}$ & 83 & $+2.9(+3.5)$ \\
\hline \multicolumn{5}{|c|}{ DPP-4 inhibitors } \\
\hline \multirow[t]{14}{*}{ Sitagliptin } & Raz et al. [37] & Sita $100 \mathrm{mg}$ & 93 & $-0.6(-0.6)$ \\
\hline & & Placebo & 90 & $-0.7(-0.8)$ \\
\hline & Aschner et al. [38] & Sita $100 \mathrm{mg}$ & 85 & $-0.2(-0.2)$ \\
\hline & & Placebo & 85 & $-1.1(-1.3)$ \\
\hline & Nauck et al. [39] & Sita $100 \mathrm{mg}+$ Met & 90 & $-1.5(-1.7)$ \\
\hline & & Glipizide + Met & 90 & $+1.1(+1.2)$ \\
\hline & Wainstein et al. [40] & $\begin{array}{l}\text { Sita } 50 \mathrm{mg}+\text { Met } 500 \mathrm{mg} \\
\text { FDC twice daily }\end{array}$ & 83 & $-1.4(1.7)$ \\
\hline & & Pio & 81 & $+3.0(3.7)$ \\
\hline & Srivastava et al. [41] & Sita & NR & -0.1 \\
\hline & & SU & NR & +0.5 \\
\hline & Pérez-Monteverde et al. & Sita + Met & 83 & $-1.1(-1.3)$ \\
\hline & & Pio & 82 & $+3.4(+4.1)$ \\
\hline & Reasner et al. [43] & $\begin{array}{l}\text { Sita } 50 \mathrm{mg}+\text { Met } 1,000 \mathrm{mg} \\
\text { FDC twice daily }\end{array}$ & NR & -1.6 \\
\hline & & Met & NR & -1.6 \\
\hline \multirow[t]{8}{*}{ Saxagliptin } & Rosenstock et al. [44] & Saxa $5 \mathrm{mg}$ & 90 & $-0.23(-0.3)$ \\
\hline & & Placebo & 93 & $-1.03(-1.1)$ \\
\hline & Chacra et al. [45] & Saxa $5 \mathrm{mg}+\mathrm{SU}$ & 76 & $+0.8(+1.1)$ \\
\hline & & Placebo + SU & 76 & $+0.3(+0.4)$ \\
\hline & Jadzinsky et al. [46] & Saxa $5 \mathrm{mg}+$ Met & 82 & $-1.8(-2.2)$ \\
\hline & & Met monotherapy & 83 & $-1.6(-1.9)$ \\
\hline & DeFronzo et al. [47] & Saxa $5 \mathrm{mg}+$ Met & 87 & $-0.87(-1.0)$ \\
\hline & & Placebo + Met & 87 & $-0.92(-1.1)$ \\
\hline \multirow[t]{15}{*}{ Linagliptin } & Del Prato et al. [48] & Lina $5 \mathrm{mg}$ & 79 & NR; NS \\
\hline & & Placebo & 79 & NR; NS \\
\hline & Taskinen et al. [49] & Lina $5 \mathrm{mg}+$ Met & 82 & $-0.4(-0.5)$ \\
\hline & & Placebo + Met & 83 & $-0.5(-0.6)$ \\
\hline & Owens et al. [50] & Lina $5 \mathrm{mg}+\mathrm{SU}$ & 77 & $+0.3(+0.4)$ \\
\hline & & Placebo + SU & 77 & $-0.1(-0.1)$ \\
\hline & Haak et al. [51] & Lina $5 \mathrm{mg}$ & 79 & $+0.2(+0.3)$ \\
\hline & & Met $1,000 \mathrm{mg}$ twice daily & 80 & $-0.5(-0.6)$ \\
\hline & & $\underset{\text { twice daily }}{\text { Lina } 2.5 \mathrm{mg}}+$ Met 1,000 mg & 77 & $-0.8(-1.0)$ \\
\hline & & Placebo & 77 & $-0.7(-0.9)$ \\
\hline & Gomis et al. [52] & Pio & 83 & $+1.3(1.6)$ \\
\hline & & Lina $5 \mathrm{mg}+$ Pio & 78 & $+2.7(3.5)$ \\
\hline & Gomis et al. $[53]^{c}$ & Lina $5 \mathrm{mg}+$ multiple: 2 years & 79 & $-0.03(0.04)$ \\
\hline & Gallwitz et al. [54] & Lina 5 mg + Met & 86 & $-1.4(1.6)$ \\
\hline & & $\mathrm{SU}+\mathrm{Met}$ & 87 & $+1.3(1.5)$ \\
\hline
\end{tabular}

$\overline{B M I}$ body mass index, Exe exenatide, $F D C$ fixed-dose combination, GLP-RA glucagon-like peptide-1 receptor agonist, Lina linagliptin, Lira liraglutide, $L M$ lifestyle management, Met metformin, NR not reported, NS non-significant, Pio pioglitazone, Rosi rosiglitazone, Sita sitagliptin, Saxa saxagliptin, SU sulfonylurea, $T Z D$ thiazolidinedione

a Glass et al.: pooled data from Nauck et al. [36] and Heine et al. [14]

${ }^{\mathrm{b}}$ Klonoff et al.: patients from Buse et al. [15], DeFronzo et al. [16], and Kendall et al. [17], continued in an extension study

${ }^{c}$ Gomis et al.: patients from Del Prato et al. [48], Taskinen et al. [49], Owens et al. [50], and Gomis et al. [52] continued in an extension study 
body weight), and daily insulin doses decreased by 39 units. The mean glycosylated hemoglobin (HbA1c) decreased from $8.9 \%$ to $7.9 \%$. Taken together, the results of this study demonstrated that the combined use of incretin therapy and insulin is more advantageous than insulin alone. This strategy was equally effective for glycemic control, lower doses of insulin were needed and, rather than gaining weight as would be expected with initiation of insulin therapy, patients actually lost weight.

\section{Blood Pressure}

The effects of incretin therapies on other CV risk factors and on immediate cardiac outcomes are subjects of ongoing research, but evidence to date has demonstrated a favorable effect on several variables. For example, in an analysis of six trials, including more than 2,000 patients treated with exenatide, the mean placeboadjusted SBP reduction was $-2.8 \mathrm{mmHg}$ [58]. Patients with baseline SBP $\geq 130 \mathrm{mmHg}$ showed mean SBP reductions of $-3.8 \mathrm{mmHg}$. A more recent meta-analysis by Vilsbøll et al. [59] reviewed the literature on twice-daily exenatide and liraglutide, demonstrating that SBP reductions in published studies range from 1 to $6 \mathrm{mmHg}$. This included analysis of the pivotal trials of exenatide [24-28] and liraglutide [18-23], in which the mean SBP was typically recorded as a secondary outcome. Comparable or better results may be expected with once-weekly exenatide; in a trial that compared once-weekly exenatide with the original twice-daily formulation, the mean SBP reductions from baseline were -2.9 and $-1.2 \mathrm{mmHg}$, respectively [28]. Multiple metaanalyses have recently been conducted in review of the CV effects of DPP-4 inhibitors [60-64]. In these reports, the mean change in
SBP was generally in the range of $1-4 \mathrm{mmHg}$ for linagliptin [61] and saxagliptin [60].

The mechanism by which these agents reduce $\mathrm{BP}$ is not yet clear. One retrospective analysis combined data from three exenatide trials $(N=686$ patients $)$ to assess the relationship among SBP reduction, weight loss, and glycemic control [65]. This study utilized a method of internal referencing, whereby patients were categorized into groups according to those achieving HbA1c reduction and weight loss greater or less than the weighted mean. Patients above the weighted mean for HbA1c reduction, weight loss, or both had, respectively, 30\%, 61\%, and 88\% higher chances of lowering SBP $<130 \mathrm{mmHg}$ (compared with those below the mean). This suggests that blood glucose-lowering and weight loss may contribute independently to BP-lowering, with synergism when both factors are combined; however, at this time, such interpretation is still preliminary and requires further study as other unknown factors may also contribute. One recent study in 61 patients receiving exenatide for a mean of 1.4 years evaluated the correlation between weight loss and SBP reduction and concluded that the BP reduction was not significantly associated with weight loss [66].

\section{Lipids}

One study reported a significant improvement in fasting TC and HDL-C with exenatide therapy [67], which is consistent with an earlier report that demonstrated significant improvements in fasting TG and TC, HDL-C, and LDL-C with this agent [34]. Postprandial measurements have also shown lipid improvement with exenatide; Meier et al. [68] reported a non-significant increase in postprandial TG $(-0.023 \mathrm{mmol} / \mathrm{L})$ versus 
baseline, compared with a significant $+0.33 \mathrm{mmol} / \mathrm{L}$ increase in the placebo group. Other exenatide studies have shown no significant change in lipid parameters $[15,16$, $29,35]$. Liraglutide therapy has been shown to improve TC and LDL-C and to significantly decrease fasting TG by up to $36 \mathrm{mg} / \mathrm{dL}[69,70]$. One of the pivotal liraglutide phase 3 studies (LEAD-6) directly compared exenatide and liraglutide, including analysis of lipid parameters [23]. Relative to exenatide, liraglutide led to a similar reduction in TC $(-0.2$ versus $-0.1 \mathrm{mmol} / \mathrm{L})$, LDL-C $\quad(-0.5$ versus $-0.4 \mathrm{mmol} / \mathrm{L})$, and TG $(-0.4$ versus $-0.2 \mathrm{mmol} / \mathrm{L}$ ).

A recent meta-analysis of the literature on DPP-4 inhibitors specifically evaluated the effects of these agents on lipid parameters [64]. This analysis concluded that treatment with DPP-4 inhibitors was associated with significant improvements in TG $(-0.1 \mathrm{mmol} / \mathrm{L})$, but not HDL-C. Although an overall significant reduction in TC $(-0.2 \mathrm{mmol} / \mathrm{L})$ was determined, evaluation of DPP-4 inhibitors on an individual basis suggested that the USapproved agents had no significant effect on TC. This report did not include data on linagliptin, although another meta-analysis by Johansen et al. [61] included an assessment of lipid data reported in published linagliptin studies. Linagliptin reduced TG by $0.1 \mathrm{mmol} / \mathrm{L}$ from baseline ( $P$ value not reported) and did not appear to influence TC.

\section{CARDIOVASCULAR EVENTS}

The effect of DPP-4 inhibitors on the occurrence of $\mathrm{CV}$ events has been retrospectively evaluated by meta-analysis [60-63]. Monami et al. [62] reviewed 33 placebo-controlled studies of DPP-4 inhibitors and, as part of their analysis, included an assessment of CV events. These authors reported an odds ratio (OR) for $\mathrm{CV}$ events of $1.04(0.70-1.55)$ versus placebo for patients taking a DPP-4 inhibitor. Meta-analyses of individual DPP-4 inhibitors have demonstrated ORs for CV events of 0.43 [95\% confidence interval (CI) $0.23,0.80]$ for saxagliptin [60], and 0.34 (95\% CI $0.16,0.70)$ for linagliptin [61]. While not drawn from prospective studies powered to specifically evaluate such outcomes, these ORs represent a significant reduction in the risk of $\mathrm{CV}$ events and merit further investigation.

To this end, several prospective clinical trials are currently in progress. The CAROLINA study (Cardiovascular Outcome Study of Linagliptin versus Glimepiride in Patients with Type 2 Diabetes; NCT01243424) has a targeted enrollment of $\sim 6,000$ patients with type 2 diabetes. With a planned duration of up to 8 years, this study will investigate the long-term impact of treatment with linagliptin on $\mathrm{CV}$ morbidity and mortality in patients with type 2 diabetes who are at an elevated CV risk and compare the outcome against treatment with the SU glimepiride. Comparable trials are also in progress for other DPP-4 inhibitors. The TECOS study (Trial Evaluating Cardiovascular Outcomes With Sitagliptin; NCT00790205) will compare the impact of usual care with and without add-on sitagliptin on CV outcomes in an estimated 14,000 patients followed for up to 5 years. SAVOR-TIMI (Saxagliptin Assessment of Vascular Outcomes Recorded in patients with diabetes mellitus-Thrombolysis In Myocardial Infarction; NCT01107886) enrolled 16,496 diabetic patients with either established $\mathrm{CV}$ disease or at high risk for $\mathrm{CV}$ events, and compared a primary composite $\mathrm{CV}$ endpoint in patients taking saxagliptin for up to 5 years versus placebo [71]. Data show that the primary non-inferiority safety endpoint has been met; saxagliptin does not increase $\mathrm{CV}$ events 
compared with placebo when added to the patient's standard-of-care regimen (with or without other antidiabetic medications). Since results did not show a decrease in the risk of overall CV events with saxagliptin versus comparators, the trial did not meet the primary efficacy objective of superiority [72].

When fully available, these studies will provide long-term data on the $\mathrm{CV}$ effects of DPP-4 inhibitors in patients with type 2 diabetes. These data will address an important need in the medical literature, particularly considering that some data have suggested an exacerbation of $\mathrm{CV}$ risk with the more commonly prescribed SUs, especially when used in combination with metformin. For example, in the UKPDS study, the early addition of metformin to an SU was associated with a $96 \%$ increase in diabetes-related deaths compared with continued SU use [73]. Later studies provided additional data that described this association. One study reported an adjusted $43 \%$ increase in total mortality and an adjusted 70\% increase in CV mortality in patients taking an SU versus metformin [74]. A retrospective review of the UK General Practice Research Database showed that the combination of metformin and SU increased mortality by $24-61 \% \quad(P=0.001)$ and heart failure by $18-30 \%$ relative to metformin monotherapy [75]. Meta-analyses on this subject have also described adverse outcomes associated with SUmetformin combination therapy [76, 77].

Considering the high prevalence of $\mathrm{CV}$ mortality in patients with diabetes, the importance of medications with favorable $\mathrm{CV}$ safety profiles cannot be understated. At the very least, medications for the treatment of diabetes should be neutral if not actively preventive with regard to $\mathrm{CV}$ risk factors and outcomes. The current literature on incretinbased therapies is promising in this respect and, in the coming years, we can expect the CV literature to provide a more detailed view of these and other antidiabetic therapies.

\section{SUSTAINABILITY OF THE PRESCRIBED REGIMEN}

Discontinuation of adherence to prescribed therapies remains an important obstacle to achieving treatment goals in patients with type 2 diabetes. Intolerability is the most common factor leading to medication discontinuation [e.g., hypoglycemia, gastrointestinal (GI) disturbances], although other factors such as natural history, complex daily regimens, out-of-pocket costs, and declining efficacy may also play a role. For example, a survey-based study of 2074 patients with type 2 diabetes found that over a 2-week period, $57 \%$ of participants reported symptoms of hypoglycemia, $28 \%$ reported constipation or diarrhea, and 21-26\% experienced headaches, water retention, or weight gain. The important finding from this study in relation to adherence was that each additional tolerability issue was associated with a $28 \%$ increase in medication non-adherence [78].

\section{Hypoglycemia}

Hypoglycemia is one of the more common tolerability/side effect issues leading to medication discontinuation. Incretin-based therapies induce the secretion of insulin from pancreatic tissue only in the presence of elevated blood glucose (e.g., 'glucosedependent insulin secretion'); these agents therefore pose a low risk for hypoglycemia. A recent claims database analysis specifically examined hypoglycemic events in more than 212,000 patients taking OADs from January 1999 through September 2008 [79]. The rates 
of hypoglycemia were significantly increased in patients taking SU compared with those not receiving SU [hazard ratio, $1.58(1.51,1.65)]$, were significantly decreased in patients taking a DPP-4 inhibitor versus those not taking a DPP-4 inhibitor [OR $0.79(0.65,0.95)]$, and were not significantly different between patients taking metformin versus those not taking metformin. Importantly, the incidence of at least one hypoglycemic event was associated with medication discontinuation. In this study, medication discontinuation was determined as a gap of $\geq 30$ days within a 6-month interval following the hypoglycemic event. Compared with patients with no hypoglycemic events, in those who had one or more episodes, the OR for medication discontinuation was 1.26 (1.22, 1.31). Given the low rates of hypoglycemia associated with incretin-based therapies, these agents may serve to improve medication adherence in patients with intolerability issues related to hypoglycemia.

\section{Medication Adherence Rates}

Although the specific metric of medication adherence may vary across studies, the consensus perspective evident in the literature is that a large proportion of patients do not continue to take the antihyperglycemic medications prescribed by their physicians for the long term. Two of the largest studies exploring medication adherence utilized the Veterans Administration (VA) database. In a study of records from more than 56,000 veterans with type 2 diabetes taking OADs (years 2000-2002), 23\% of patients were categorized as non-adherent, as defined by a medication possession ratio (MPR) $<80 \%$ after 1 year [80]. A later re-evaluation of the VA database (years 2005-2007) demonstrated a somewhat higher rate of non-adherence (30\%) using the 1-year MPR $(N=444,418)$ [81]. One study that reviewed the medical literature for data on adherence (years 2000-2005) reported similar results, showing that $42 \%$ of patients had a 1-year MPR $<80 \%$ (35 studies) [82]. Based on only these results, one might conclude that approximately one-third of patients with type 2 diabetes can be expected to take less than $80 \%$ of their prescribed medication. A more recent study of patients taking exenatide $(n=3,262)$ compared adherence rates with patients taking insulin glargine $(n=3,038)$ [83]. Using the 1-year MPR, $32 \%$ of patients taking exenatide and $42 \%$ taking glargine were categorized as non-adherent.

Although there are no studies that specifically evaluate adherence rates in patients taking DPP-4 inhibitors, several publications have reviewed the discontinuation and adverse event (AE) rates of these agents in clinical trials. For example, Karagiannis et al. [84] reported that AE-related discontinuation rates in trials of DPP-4 inhibitors (nine sitagliptin studies, six vildagliptin studies, three saxagliptin studies, and one linagliptin study) were lower than in patients taking metformin monotherapy (relative risk 0.69, 0.51-0.94). Recently, SinghFranco et al. [85] reported another metaanalysis that included an assessment of discontinuation rates in five published and four unpublished trials of linagliptin. The overall rate of AEs in this analysis was not significantly different from placebo, nor were withdrawals due to AEs significantly different between linagliptin (2.4\%) and placebo (3.1\%), which is consistent with the results of another meta-analysis of linagliptin trials $[85,86]$. A pooled analysis of data from sitagliptin trials ( $N=10,246$ patients with type 2 diabetes) showed that the rates of discontinuation due to AEs were similar in patients receiving 
sitagliptin versus comparators $(4.4 \%$ versus $4.5 \%$, respectively) [87]. These results are consistent with data from meta-analyses and systematic reviews showing an acceptable safety and tolerability profile for DPP-4 inhibitors [63, 84].

Within the incretin-mimetics class, the most commonly occurring tolerability issue stems from GI side effects (e.g., nausea, abdominal discomfort, and vomiting) [88]. These may occur in up to $30 \%$ of patients, although the incidence of GI symptoms usually declines within the first month of therapy [89-91]. No studies have yet been published that describe adherence rates in patients taking the recently approved once-weekly formulation of exenatide. However, provided that the efficacy, $\mathrm{AE}$ profile, and rate of discontinuation of the once-weekly formulation is not significantly different from the older twice-daily formulation [92], it may be expected that patient adherence to the onceweekly formulation may be improved as a result of its simpler dosing schedule.

Lastly, it has been shown that simplification of the dosing schedule can lead to significant improvements in medication adherence using fixed-dose combination (FDC) therapies. For example, a retrospective database review recently showed that patients with diabetes who were categorized by their physicians as adherent to their prescribed antihyperglycemic medication regimen were five times more likely to be taking an FDC than those who were described by physicians as non-adherent [93]. Initiation of treatment with an FDC is associated with greater adherence when compared with patients receiving the same medications as 'loose-pill combination.' Authors of an analysis of seven studies that compared these strategies concluded that adherence was $13 \%$ greater in patients who started on FDCs [94]. Cheong et al. [95] demonstrated that when patients already taking loose-pill combinations $(N=14,762)$ were switched to a comparable FDC $(N=7,570)$, adherence increased by $12 \%$.

Each of the four Food and Drug Administration-approved DPP-4 inhibitors has been developed with an FDC formulation (combination with metformin). Thus, when considered along with their excellent tolerability profiles, the availability of FDCs with these agents proffers a means of increasing medication adherence in patients with type 2 diabetes.

\section{CONCLUSION}

Diabetes is a multifactorial disease with a high prevalence of comorbidities resulting from hypertension, dyslipidemia, and hyperglycemia. Inadequate management of these three physiologic risk factors in patients with type 2 diabetes will eventually lead to a debilitating loss of function in multiple organ systems. Therefore, each of these risk factors must be brought under control as early as possible following diagnosis, and their control must be maintained throughout the course of the disease. Emphasis in the medical literature has tended to focus on glycemic control, in part due to the rapid expansion of the number of antidiabetic agents that require evaluation of efficacy. However, in recent years, it has become evident that key pharmacologic characteristics of antihyperglycemic medications reach beyond an effect on blood glucose. The assessment of new medications for the treatment of type 2 diabetes is now more comprehensive than in the earlier decades of OAD research. The GLP-1RA and the DPP-4 inhibitors are the first classes of new antidiabetes treatments that needed 
demonstration of $\mathrm{CV}$ safety as a regulatory approval requirement. Moreover, long-term safety trials are in progress, with results from the first studies showing no increase in overall CV risk $[72,96]$. Thus, we have at our disposal a wealth of information describing the range of actions of glucose-lowering medications in patients with type 2 diabetes.

Guidelines from the American Diabetes Association and the American Association of Clinical Endocrinologists (AACE) stress an individualized approach to care, which includes consideration of patient preferences, medication cost, potential class-related side effects, and the effects of treatments on body weight and hypoglycemia risk [56, 97]. In the AACE algorithm, GLP-1RA and DPP-4 inhibitors are recommended after metformin based on their therapeutic profiles indicating few AEs or possible benefits [97]. For GLP-1RA, added benefits include weight loss, improvement in $\mathrm{BP}$, and a decrease in inflammatory markers. The side effect profile for GLP-1RAs, however, can be difficult for some patients because of the potential for nausea, and even vomiting. Patients also may be resistant to an injectable therapy. For DPP-4s, benefits include oral administration with good patient acceptance and an excellent tolerability profile, resulting in few patient requests to switch therapy. When discussing therapy options, a patient-centered communication style focused on the patient's foremost problems and how they are feeling physically is important [98]. Clinicians can use practical terms about how incretin therapy options address patient concerns, such as fear of weight gain with add-on therapy. The underlying mechanisms of incretin-based therapies may represent a novel approach to the management of type 2 diabetes, given that these agents may act through multiple signaling pathways to effect changes not only in glucose homeostasis, but possibly in other physiologic processes as well. For example, there is some evidence that GLP-1 receptors may have a direct influence in BP regulation and other cardiac functions [99]. In addition, whether GLP-1RAs and DPP-4 inhibitors have a direct effect on blood lipids seems an unanswered question, with some studies reporting null and others significant results. However, in the near future, we may expect a clearer understanding of these extraglycemic effects of incretin therapies and, for the time being, our task is to tailor best practices to fit the current evidence.

The synthesis resulting from this review of the literature yields two main conclusions about the extraglycemic effects of incretin therapies. In addition to their well-known influence on the maintenance or loss of weight, the use of GLP-1RAs and DPP-4 inhibitors appears to be associated with a modest decrease in BP and a reduced risk for $\mathrm{CV}$ events. Secondly, several characteristics of incretin therapies may improve rates of medication adherence such as the availability of formulations that simplify treatment regimens (e.g., once-weekly exenatide, DPP-4/metformin FDCs), a low risk for hypoglycemia, and generally favorable tolerability profiles, particularly with DPP-4 inhibitors.

\section{ACKNOWLEDGMENTS}

The author was fully responsible for all content and editorial decisions, was involved at all stages of manuscript development, and has approved the final version of the review that reflects his interpretation and conclusions. Dr. Davidson is the guarantor for this article, and takes responsibility for the integrity of the work as a whole. Medical writing assistance during the preparation of this review was provided by Michael P. Bennett of Envision Scientific 
Solutions, supported financially by Boehringer Ingelheim Pharmaceuticals, Inc. Boehringer Ingelheim Pharmaceuticals Inc was given the opportunity to check the data used in the manuscript for factual accuracy only. Sponsorship and article processing charges for this study were funded by Boehringer Ingelheim Pharmaceuticals, Inc.

Conflict of interest. Jaime Davidson is a consultant, advisory board member, and/or speaker's bureau member for the following companies: Animas, Allergan, AstraZeneca, Boehringer Ingelheim, Bristol-Myers Squibb, Eli Lilly \& Co., Johnson \& Johnson (LifeScan), Merck Serono, Merck, Sharp, \& Dohme, Novo Nordisk, Novartis, Roche/Roche Diagnostic, and Sanofi-Aventis.

Open Access. This article is distributed under the terms of the Creative Commons Attribution Noncommercial License which permits any noncommercial use, distribution, and reproduction in any medium, provided the original author(s) and the source are credited.

\section{REFERENCES}

1. American Diabetes Association. Diabetic nephropathy. Diabetes Care. 2002;25:S85-9.

2. Laliberté F, Bookhart BK, Vekeman F, et al. Direct all-cause health care costs associated with chronic kidney disease in patients with diabetes and hypertension: a managed care perspective. J Manag Care Pharm. 2009;15:312-22.

3. Yau JW, Xie J, Lamoureux E, et al. Retinal microvascular calibre and risk of incident diabetes: the multi-ethnic study of atherosclerosis. Diabetes Res Clin Pract. 2012;95:265-74.

4. Saaddine JB, Honeycutt AA, Narayan KM, Zhang X, Klein R, Boyle JP. Projection of diabetic retinopathy and other major eye diseases among people with diabetes mellitus: United States, 2005-2050. Arch Ophthalmol. 2008;126:1740-7.
5. Abdullah A, Peeters A, de Courten M, Stoelwinder J. The magnitude of association between overweight and obesity and the risk of diabetes: a meta-analysis of prospective cohort studies. Diabetes Res Clin Pract. 2010;89:309-19.

6. Centers for Disease Control and Prevention. Prevalence of self-reported cardiovascular disease among persons aged $>$ or $=35$ years with diabetesUnited States, 1997-2005. MMWR Morb Mortal Wkly Rep. 2007;56:1129-32.

7. Unick JL, Beavers D, Jakicic JM, et al. Effectiveness of lifestyle interventions for individuals with severe obesity and type 2 diabetes: results from the Look AHEAD trial. Diabetes Care. 2011;34:2152-7.

8. Adler AI, Stratton IM, Neil HA, et al. Association of systolic blood pressure with macrovascular and microvascular complications of type 2 diabetes (UKPDS 36): prospective observational study. BMJ. 2000;321:412-9.

9. Third Report of the National Cholesterol Education Program (NCEP) Expert Panel on Detection, Evaluation, and Treatment of High Blood Cholesterol in Adults (Adult Treatment Panel III) final report. Circulation. 2002;106:3143-421.

10. Law MR. Lowering heart disease risk with cholesterol reduction: evidence from observational studies and clinical trials. Eur Heart J Suppl. 1999;(Suppl S):S3-8.

11. Law MR, Thompson SG, Wald NJ. Assessing possible hazards of reducing serum cholesterol. BMJ. 1994;308:373-9.

12. Law MR, Wald NJ, Thompson SG. By how much and how quickly does reduction in serum cholesterol concentration lower risk of ischaemic heart disease? BMJ. 1994;308:367-72.

13. U.S. Department of Health and Human Services. NIH News. Weight loss does not lower heart disease risk from type 2 diabetes. http://www.nih.gov/ news/health/oct2012/niddk-19.htm (Accessed 9 May 2013).

14. Heine RJ, Van Gaal LF, Johns D, Mihm MJ, Widel $\mathrm{MH}$, Brodows RG. Exenatide versus insulin glargine in patients with suboptimally controlled type 2 diabetes: a randomized trial. Ann Intern Med. 2005;143:559-69.

15. Buse JB, Henry RR, Han J, et al. Effects of exenatide (exendin-4) on glycemic control over 30 weeks in sulfonylurea-treated patients with type 2 diabetes. Diabetes Care. 2004;27:2628-35.

16. DeFronzo RA, Ratner RE, Han J, Kim DD, Fineman MS, Baron AD. Effects of exenatide (exendin-4) on 
glycemic control and weight over 30 weeks in metformin-treated patients with type 2 diabetes. Diabetes Care. 2005;28:1092-100.

17. Kendall DM, Riddle MC, Rosenstock J, et al. Effects of exenatide (exendin-4) on glycemic control over 30 weeks in patients with type 2 diabetes treated with metformin and a sulfonylurea. Diabetes Care. 2005;28:1083-91.

18. Marre M, Shaw J, Brändle $M$, et al. Liraglutide, a once-daily human GLP-1 analogue, added to a sulphonylurea over 26 weeks produces greater improvements in glycaemic and weight control compared with adding rosiglitazone or placebo in subjects with Type 2 diabetes (LEAD-1 SU). Diabet Med. 2009;26:268-78.

19. Nauck M, Frid A, Hermansen K, et al. Efficacy and safety comparison of liraglutide, glimepiride, and placebo, all in combination with metformin, in type 2 diabetes: the LEAD (liraglutide effect and action in diabetes)-2 study. Diabetes Care. 2009;32:84-90.

20. Garber A, Henry R, Ratner R, et al. Liraglutide versus glimepiride monotherapy for type 2 diabetes (LEAD-3 Mono): a randomised, 52-week, phase III, double-blind, parallel-treatment trial. Lancet. 2009;373:473-81.

21. Zinman B, Gerich J, Buse JB, et al. Efficacy and safety of the human glucagon-like peptide-1 analog liraglutide in combination with metformin and thiazolidinedione in patients with type 2 diabetes (LEAD-4 Met + TZD). Diabetes Care. 2009;32:1224-30.

22. Russell-Jones D, Vaag A, Schmitz O, et al. Liraglutide vs insulin glargine and placebo in combination with metformin and sulfonylurea therapy in type 2 diabetes mellitus (LEAD-5 met + SU): a randomised controlled trial. Diabetologia. 2009;52:2046-55.

23. Buse JB, Rosenstock J, Sesti G, et al. Liraglutide once a day versus exenatide twice a day for type 2 diabetes: a 26-week randomised, parallel-group, multinational, open-label trial (LEAD-6). Lancet. 2009;374:39-47.

24. Buse JB, Drucker DJ, Taylor KL, et al. DURATION-1: exenatide once weekly produces sustained glycemic control and weight loss over 52 weeks. Diabetes Care. 2010;33:1255-61.

25. Bergenstal RM, Wysham C, Macconell L, et al. Efficacy and safety of exenatide once weekly versus sitagliptin or pioglitazone as an adjunct to metformin for treatment of type 2 diabetes (DURATION-2): a randomised trial. Lancet. 2010;376:431-9.
26. Diamant M, Van Gaal L, Stranks S, et al. Once weekly exenatide compared with insulin glargine titrated to target in patients with type 2 diabetes (DURATION-3): an open-label randomised trial. Lancet. 2010;375:2234-43.

27. Russell-Jones D, Cuddihy RM, Hanefeld M, et al. Efficacy and safety of exenatide once weekly versus metformin, pioglitazone, and sitagliptin used as monotherapy in drug-naive patients with type 2 diabetes (DURATION-4): a 26-week double-blind study. Diabetes Care. 2012;35:252-8.

28. Blevins T, Pullman J, Malloy J, et al. DURATION-5: exenatide once weekly resulted in greater improvements in glycemic control compared with exenatide twice daily in patients with type 2 diabetes. J Clin Endocrinol Metab. 2011;96:1301-10.

29. Apovian CM, Bergenstal RM, Cuddihy RM, et al. Effects of exenatide combined with lifestyle modification in patients with type 2 diabetes. Am J Med. 2010;123:468 e9-17.

30. Bunck MC, Corner A, Eliasson B, et al. One-year treatment with exenatide vs. insulin glargine: effects on postprandial glycemia, lipid profiles, and oxidative stress. Atherosclerosis. 2010;212:223-9.

31. Davies MJ, Donnelly R, Barnett AH, Jones S, Nicolay C, Kilcoyne A. Exenatide compared with longacting insulin to achieve glycaemic control with minimal weight gain in patients with type 2 diabetes: results of the Helping Evaluate Exenatide in patients with diabetes compared with LongActing insulin (HEELA) study. Diabetes Obes Metab. 2009; 11:1153-62.

32. Gallwitz B, Böhmer M, Segiet $T$, et al. Exenatide twice daily versus premixed insulin aspart 70/30 in metformin-treated patients with type 2 diabetes: a randomized 26-week study on glycemic control and hypoglycemia. Diabetes Care. 2011;34:604-6.

33. Glass LC, Qu Y, Lenox S, et al. Effects of exenatide versus insulin analogues on weight change in subjects with type 2 diabetes: a pooled post hoc analysis. Curr Med Res Opin. 2008;24:639-44.

34. Klonoff DC, Buse JB, Nielsen LL, et al. Exenatide effects on diabetes, obesity, cardiovascular risk factors and hepatic biomarkers in patients with type 2 diabetes treated for at least 3 years. Curr Med Res Opin. 2008;24:275-86.

35. Moretto TJ, Milton DR, Ridge TD, et al. Efficacy and tolerability of exenatide monotherapy over 24 weeks in antidiabetic drug-naive patients with type 2 diabetes: a randomized, double-blind, placebo-controlled, parallel-group study. Clin Ther. 2008;30:1448-60. 
36. Nauck MA, Duran S, Kim D, et al. A comparison of twice-daily exenatide and biphasic insulin aspart in patients with type 2 diabetes who were suboptimally controlled with sulfonylurea and metformin: a non-inferiority study. Diabetologia. 2007;50:259-67.

37. Raz I, Hanefeld M, Xu L, Caria C, Williams-Herman D, Khatami H. Efficacy and safety of the dipeptidyl peptidase-4 inhibitor sitagliptin as monotherapy in patients with type 2 diabetes mellitus. Diabetologia. 2006;49:2564-71.

38. Aschner P, Kipnes MS, Lunceford JK, et al. Effect of the dipeptidyl peptidase- 4 inhibitor sitagliptin as monotherapy on glycemic control in patients with type 2 diabetes. Diabetes Care. 2006;29:2632-7.

39. Nauck MA, Meininger G, Sheng D, Terranella L, Stein PP. Efficacy and safety of the dipeptidyl peptidase- 4 inhibitor, sitagliptin, compared with the sulfonylurea, glipizide, in patients with type 2 diabetes inadequately controlled on metformin alone: a randomized, double-blind, non-inferiority trial. Diabetes Obes Metab. 2007;9:194-205.

40. Wainstein J, Katz L, Engel SS, et al. Initial therapy with the fixed-dose combination of sitagliptin and metformin results in greater improvement in glycaemic control compared with pioglitazone monotherapy in patients with type 2 diabetes. Diabetes Obes Metab. 2012;14:409-18.

41. Srivastava S, Saxena GN, Keshwani P, Gupta R. Comparing the efficacy and safety profile of sitagliptin versus glimepiride in patients of type 2 diabetes mellitus inadequately controlled with metformin alone. J Assoc Physicians India. 2012;60:27-30.

42. Pérez-Monteverde A, Seck T, Xu L, et al. Efficacy and safety of sitagliptin and the fixed-dose combination of sitagliptin and metformin vs. pioglitazone in drug-naive patients with type 2 diabetes. Int J Clin Pract. 2011;65:930-8.

43. Reasner C, Olansky L, Seck TL, et al. The effect of initial therapy with the fixed-dose combination of sitagliptin and metformin compared with metformin monotherapy in patients with type 2 diabetes mellitus. Diabetes Obes Metab. 2011;13:644-52.

44. Rosenstock J, Sankoh S, List JF. Glucose-lowering activity of the dipeptidyl peptidase-4 inhibitor saxagliptin in drug-naive patients with type 2 diabetes. Diabetes Obes Metab. 2008;10:376-86.

45. Chacra AR, Tan GH, Apanovitch A, et al. Saxagliptin added to a submaximal dose of sulphonylurea improves glycaemic control compared with uptitration of sulphonylurea in patients with type 2 diabetes: a randomised controlled trial. Int J Clin Pract. 2009;63(9):1395-406.

46. Jadzinsky M, Pfützner A, Paz-Pacheco E, et al. Saxagliptin given in combination with metformin as initial therapy improves glycaemic control in patients with type 2 diabetes compared with either monotherapy: a randomized controlled trial. Diabetes Obes Metab. 2009;11:611-22.

47. DeFronzo RA, Hissa MN, Garber AJ, et al. The efficacy and safety of saxagliptin when added to metformin therapy in patients with inadequately controlled type 2 diabetes with metformin alone. Diabetes Care. 2009;32:1649-55.

48. Del Prato S, Barnett AH, Huisman H, Neubacher D, Woerle HJ, Dugi KA. Effect of linagliptin monotherapy on glycaemic control and markers of beta-cell function in patients with inadequately controlled type 2 diabetes: a randomized controlled trial. Diabetes Obes Metab. 2011;13:258-67.

49. Taskinen MR, Rosenstock J, Tamminen I, et al. Safety and efficacy of linagliptin as add-on therapy to metformin in patients with type 2 diabetes: a randomized, double-blind, placebo-controlled study. Diabetes Obes Metab. 2011;13:65-74.

50. Owens DR, Swallow R, Dugi KA, Woerle HJ. Efficacy and safety of linagliptin in persons with type 2 diabetes inadequately controlled by a combination of metformin and sulphonylurea: a 24-week randomized study. Diabet Med. 2011;28:1352-61.

51. Haak T, Meinicke T, Jones R, Weber S, von Eynatten $\mathrm{M}$, Woerle HJ. Initial combination of linagliptin and metformin improves glycaemic control in type 2 diabetes: a randomized, double-blind, placebocontrolled study. Diabetes Obes Metab. 2012;14:565-74.

52. Gomis R, Espadero RM, Jones R, Woerle HJ, Dugi KA. Efficacy and safety of initial combination therapy with linagliptin and pioglitazone in patients with inadequately controlled type 2 diabetes: a randomized, double-blind, placebocontrolled study. Diabetes Obes Metab. 2011;13:653-61.

53. Gomis R, Owens DR, Taskinen MR, et al. Long-term safety and efficacy of linagliptin as monotherapy or in combination with other oral glucose-lowering agents in 2121 subjects with type 2 diabetes: up to 2 years exposure in 24 -week phase III trials followed by a 78-week open-label extension. Int J Clin Pract. 2012;66:731-40.

54. Gallwitz B, Rosenstock J, Rauch T, et al. 2-year efficacy and safety of linagliptin compared with glimepiride in patients with type 2 diabetes 
inadequately controlled on metformin: a randomised, double-blind, non-inferiority trial. Lancet. 2012;380:475-83.

55. Niswender K, Pi-Sunyer X, Buse J, et al. Weight change with liraglutide and comparator therapies: an analysis of seven phase 3 trials from the liraglutide diabetes development programme. Diabetes Obes Metab. 2013;15:42-54.

56. Inzucchi SE, Bergenstal RM, Buse JB, et al. Management of hyperglycemia in type 2 diabetes: a patient-centered approach: position statement of the American Diabetes Association (ADA) and the European Association for the Study of Diabetes (EASD). Diabetes Care. 2012;35:1364-79.

57. Lind M, Jendle J, Torffvit O, Lager I. Glucagon-like peptide 1 (GLP-1) analogue combined with insulin reduces HbA1c and weight with low risk of hypoglycemia and high treatment satisfaction. Prim Care Diabetes. 2012;6:41-6.

58. Okerson T, Yan P, Stonehouse A, Brodows R. Effects of exenatide on systolic blood pressure in subjects with type 2 diabetes. Am J Hypertens. 2010;23:334-9.

59. Vilsbøll T, Christensen M, Junker AE, Knop FK, Gluud LL. Effects of glucagon-like peptide-1 receptor agonists on weight loss: systematic review and meta-analyses of randomised controlled trials. BMJ. 2012;344:d7771.

60. Cobble ME, Frederich R. Saxagliptin for the treatment of type 2 diabetes mellitus: assessing cardiovascular data. Cardiovasc Diabetol. 2012;11:6.

61. Johansen OE, Neubacher D, von Eynatten M, Patel S, Woerle HJ. Cardiovascular safety with linagliptin in patients with type 2 diabetes mellitus: a prespecified, prospective, and adjudicated metaanalysis of a phase 3 programme. Cardiovasc Diabetol. 2012;11:3.

62. Monami M, Cremasco F, Lamanna C, Marchionni N, Mannucci E. Predictors of response to dipeptidyl peptidase- 4 inhibitors: evidence from randomized clinical trials. Diabetes Metab Res Rev. 2011;27:362-72.

63. Monami M, Iacomelli I, Marchionni N, Mannucci E. Dipeptydil peptidase-4 inhibitors in type 2 diabetes: a meta-analysis of randomized clinical trials. Nutr Metab Cardiovasc Dis. 2010;20:224-35.

64. Monami M, Lamanna C, Desideri CM, Mannucci E. DPP-4 inhibitors and lipids: systematic review and meta-analysis. Adv Ther. 2012;29:14-25.

65. Paul S, Best J, Klein K, Han J, Maggs D. Effects of $\mathrm{HbA}(1 \mathrm{c})$ and weight reduction on blood pressure in patients with type 2 diabetes mellitus treated with exenatide $\left(^{*}\right)$ Diabetes Obes Metab. 2012;14:826-34.

66. Varanasi A, Chaudhuri A, Dhindsa $\mathrm{S}$, et al. Durability of effects of exenatide treatment on glycemic control, body weight, systolic blood pressure, C-reactive protein, and triglyceride concentrations. Endocr Pract. 2011;17:192-200.

67. Kadowaki T, Namba M, Yamamura A, Sowa $H$, Wolka AM, Brodows RG. Exenatide exhibits dosedependent effects on glycemic control over 12 weeks in Japanese patients with suboptimally controlled type 2 diabetes. Endocr J. 2009;56:415-24.

68. Meier JJ, Gethmann A, Gotze O, et al. Glucagon-like peptide 1 abolishes the postprandial rise in triglyceride concentrations and lowers levels of non-esterified fatty acids in humans. Diabetologia. 2006;49:452-8.

69. Varanasi A, Patel P, Makdissi A, Dhindsa S, Chaudhuri A, Dandona P. Clinical use of liraglutide in type 2 diabetes and its effects on cardiovascular risk factors. Endocr Pract. 2012;18:140-5.

70. Kesavadev J, Shankar A, Krishnan G, Jothydev S. Liraglutide therapy beyond glycemic control: an observational study in Indian patients with type 2 diabetes in real world setting. Int J Gen Med. 2012;5:317-22.

71. Mosenzon O, Raz I, Scirica BM, et al. Baseline characteristics of the patient population in the Saxagliptin Assessment of Vascular Outcomes Recorded in patients with diabetes mellitus (SAVOR)-TIMI 53 trial. Diabetes Metab Res Rev. 2013;29:417-26.

72. Scirica BM, Bhatt DL, Braunwald E, et al; SAVORTIMI 53 Steering committee and Investigators. Saxagliptin and cardiovascular outcomes in patients with type 2 diabetes mellitus. N Engl J Med. 2013 (Epub ahead of print).

73. UK Prospective Diabetes Study (UKPDS) Group. Effect of intensive blood-glucose control with metformin on complications in overweight patients with type 2 diabetes (UKPDS 34). Lancet. 1998;352:854-65.

74. Evans JM, Ogston SA, Emslie-Smith A, Morris AD. Risk of mortality and adverse cardiovascular outcomes in type 2 diabetes: a comparison of patients treated with sulfonylureas and metformin. Diabetologia. 2006;49:930-6.

75. Tzoulaki I, Molokhia M, Curcin V, et al. Risk of cardiovascular disease and all cause mortality 
among patients with type 2 diabetes prescribed oral antidiabetes drugs: retrospective cohort study using UK general practice research database. BMJ. 2009;339:b4731.

76. Rao AD, Kuhadiya N, Reynolds K, Fonseca VA. Is the combination of sulfonylureas and metformin associated with an increased risk of cardiovascular disease or all-cause mortality?: a meta-analysis of observational studies. Diabetes Care. 2008;31:1672-8.

77. Lamanna C, Monami M, Marchionni N, Mannucci E. Effect of metformin on cardiovascular events and mortality: a meta-analysis of randomized clinical trials. Diabetes Obes Metab. 2011;13:221-8.

78. Pollack MF, Purayidathil FW, Bolge SC, Williams SA. Patient-reported tolerability issues with oral antidiabetic agents: associations with adherence; treatment satisfaction and health-related quality of life. Diabetes Res Clin Pract. 2010;87:204-10.

79. Bron M, Marynchenko M, Yang H, Yu AP, Wu EQ. Hypoglycemia, treatment discontinuation, and costs in patients with type 2 diabetes mellitus on oral antidiabetic drugs. Postgrad Med. 2012;124:124-32.

80. Kim N, Agostini JV, Justice AC. Refill adherence to oral hypoglycemic agents and glycemic control in veterans. Ann Pharmacother. 2010;44:800-8.

81. Wong ES, Piette JD, Liu CF, et al. Measures of adherence to oral hypoglycemic agents at the primary care clinic level: the role of risk adjustment. Med Care. 2012;50:591-8.

82. Cramer JA, Benedict A, Muszbek N, Keskinaslan A, Khan ZM. The significance of compliance and persistence in the treatment of diabetes, hypertension and dyslipidaemia: a review. Int J Clin Pract. 2008;62:76-87.

83. Fabunmi R, Nielsen LL, Quimbo R, et al. Patient characteristics, drug adherence patterns, and hypoglycemia costs for patients with type 2 diabetes mellitus newly initiated on exenatide or insulin glargine. Curr Med Res Opin. 2009;25:777-86.

84. Karagiannis T, Paschos P, Paletas K, Matthews DR, Tsapas A. Dipeptidyl peptidase-4 inhibitors for treatment of type 2 diabetes mellitus in the clinical setting: systematic review and metaanalysis. BMJ. 2012;344:e1369.

85. Singh-Franco D, McLaughlin-Middlekauff J, Elrod S, Harrington C. The effect of linagliptin on glycaemic control and tolerability in patients with type 2 diabetes mellitus: a systematic review and metaanalysis. Diabetes Obes Metab. 2012;14:694-708.
86. Schernthaner G, Barnett AH, Emser A, et al. Safety and tolerability of linagliptin: a pooled analysis of data from randomized controlled trials in 3572 patients with type 2 diabetes mellitus. Diabetes Obes Metab. 2012;14:470-8.

87. Williams-Herman D, Engel SS, Round E, et al. Safety and tolerability of sitagliptin in clinical studies: a pooled analysis of data from 10,246 patients with type 2 diabetes. BMC Endocr Disord. 2010;10:7.

88. Amylin Pharmaceuticals. Byetta (exenatide) package insert. http://www.accessdata.fda.gov/drug satfda_docs/label/2009/021773s9s11s18s22s25lbl. pdf (Accessed 9 May 2013).

89. Macconell L, Brown C, Gurney K, Han J. Safety and tolerability of exenatide twice daily in patients with type 2 diabetes: integrated analysis of 5594 patients from 19 placebo-controlled and comparatorcontrolled clinical trials. Diabetes Metab Syndr Obes. 2012;5:29-41.

90. Horowitz M, Vilsbøll T, Zdravkovic M, Hammer M, Madsbad S. Patient-reported rating of gastrointestinal adverse effects during treatment of type 2 diabetes with the once-daily human GLP-1 analogue, liraglutide. Diabetes Obes Metab. 2008;10:593-6.

91. Blonde L, Russell-Jones D. The safety and efficacy of liraglutide with or without oral antidiabetic drug therapy in type 2 diabetes: an overview of the LEAD 1-5 studies. Diabetes Obes Metab. 2009;11(Suppl 3):26-34.

92. Ridge T, Moretto T, Macconell L, et al. Comparison of safety and tolerability with continuous (exenatide once weekly) or intermittent (exenatide twice daily) GLP-1 receptor agonism in patients with type 2 diabetes. Diabetes Obes Metab. 2012;14:1097-103.

93. Benford M, Milligan G, Pike J, Anderson P, Piercy J, Fermer S. Fixed-dose combination antidiabetic therapy: real-world factors associated with prescribing choices and relationship with patient satisfaction and compliance. Adv Ther. 2012;29:26-40.

94. Hutchins V, Zhang B, Fleurence RL, Krishnarajah G, Graham J. A systematic review of adherence, treatment satisfaction and costs, in fixed-dose combination regimens in type 2 diabetes. Curr Med Res Opin. 2011;27:1157-68.

95. Cheong C, Barner JC, Lawson KA, Johnsrud MT. Patient adherence and reimbursement amount for antidiabetic fixed-dose combination products compared with dual therapy among Texas Medicaid recipients. Clin Ther. 2008;30:1893907. 
96. White WB, Cannon $\mathrm{CP}$, Heller SR, et al; the EXAMINE Investigators. Alogliptin after acute coronary syndrome in patients with type 2 diabetes. N Engl J Med. 2013 (Epub ahead of print).

97. Garber AJ, Abrahamson MJ, Barzilay JI, et al. AACE comprehensive diabetes management algorithm 2013. Endocr Pract. 2013;19:327-36.
98. Kruse RL, Olsberg JE, Oliver DP, Shigaki CL, VetterSmith MJ, LeMaster JW. Patient-provider communication about diabetes self-care activities. Fam Med. 2013;45:319-22.

99. Mannucci E, Dicembrini I. Incretin-based therapies and cardiovascular risk. Curr Med Res Opin. 2012;28:715-21. 